\title{
Assessment and classification of never operated and recurrent cryptoglandular fistulas-in-ano using hydrogen peroxide enhanced transanal ultrasound
}

\author{
C. E. J. Sloots $\dagger+$, R. J. F. Felt-Bersma $\dagger+$, A. C. Poen $\dagger$ and M. A. Cuesta* \\ Departments of *Surgery and †Gastroenterology, 'Vrije Universiteit' Medical Centre, Amsterdam and łDepartment of Gastroenterology and \\ Hepatology, Erasmus Medical Centre, Rotterdam, the Netherlands \\ Received 13 November 2000; accepted 25 March 2001
}

\begin{abstract}
Objective Classification and visualization of fistula-in ano is used to determine surgical treatment according to the type of fistula, predict the recurrence rate and incontinence risk and compare the results of treatment published in literature. Hydrogen peroxide enhanced transanal ultrasound (HPUS) with the peroxide introduced through the external opening of the fistula gives a clear and accurate visualization of the track in relation to the sphincters. The aim of this study was to review never operated and recurrent cryptoglandular fistulas-in-ano visualized with the aid of HPUS in order to establish the anatomical differences.
\end{abstract}

Patients and methods Eighty-one patients with never operated (48) or recurrent (33) cryptoglandular fistulasin-ano were assessed by clinical examination and HPUS.

Results Never operated fistulas were single track, transor inter-sphincteric fistulas in $80 \%$. In $15 \%$, the tracks were sinus with no connection to the pectinate line. Two patients $(5 \%)$ had a transsphincteric fistula with a ramification. No supra- or extra-sphincteric fistulas were found in the never operated fistula group. In the recurrent fistula patients, $57 \%$ had a single trans or intersphincteric track, $15 \%$ of the patients had a single track supra or extrasphincteric fistula and $27 \%$ had a ramified fistula.

Conclusions All never operated cryptoglandulair fistulas-in-ano were inter- or trans-sphincteric. An extra track was found in 5\%. Recurrent fistulas-in-ano were supra or extrasphincteric in $15 \%$ and ramified in $27 \%$. Therefore, never operated fistula-in-ano does not require any special investigation before surgical treatment. However, before treating recurrent fistulas, visualization by HPUS is recommended to detect supra or extrasphincteric fistulas or ramification.

Keywords Fistula-in-ano, hydrogen peroxide enhanced transanal ultrasound, classification

\section{Introduction}

Classification of fistulas-in-ano is used to determine (surgical) therapy, make a prognosis concerning recurrence and fecal incontinence, and compare the results published in the literature. In 1976 Parks presented a classification of fistulas-in-ano which is still universally used today [1]. He proposed dividing the fistulas anatomically in inter, trans, supra and extrasphincteric fistulas. This anatomical classification was determined during the operation by the direction of the probe

Correspondence to: Dr R. J. F. Felt-Bersma, Gastroenterologist, Department of Gastroenterology and Hepatology, Erasmus Medical Centre, Postbus 20403000 CA Rotterdam, the Netherlands.

E-mail: Felt@mdl.azr.nl introduced into the track in relation to the anal canal and the amount of sphincter mass divided during surgery. However, pathogenesis of the fistulas was not taken into account in this classification.

Since a different pathophysiology exists for each of these different fistulas, it is clear that anatomical spread and localization may be different as well. A better understanding of this relation will permit a more simple classification in order to facilitate a practical surgical approach. Hydrogen peroxide enhanced transanal ultrasound (HPUS) is an excellent method to classify perianal fistulas and it correlates well with surgical findings as we and others have demonstrated [2-5]. In addition, HPUS is more accurate than endosonography without HPUS and digital examination [5]. Also, 
HPUS can visualize complex fistulas which helps to direct the surgeon to the difficult branches. The aim of this study is to determine the differences in fistula tracks between the never operated and recurrent fistulas and to make recommendations about the need for pre-operative imaging.

\section{Patients and methods}

\section{Patients}

Eighty-one patients with fistula-in-ano (65 males and 16 females; mean age 46 years range 22-79) were assessed by history, physical examination, probing of the fistula track, proctoscopy and HPUS. In patients with a recurrence, Crohn's disease was excluded by patient history, physical examination, enteroclysis and endoscopy.

\section{Physical examination}

The perineal region was inspected for visualization of the external opening and digital examination was performed with careful probing of the fistula track. During the digital examination, the presence of the internal opening (induration) was recorded as well as the palpation of the tip of the passing probe in the anal canal.

\section{Proctoscopy}

Proctoscopy was performed to exclude proctitis and anal malignancy, and to evaluate of the internal opening of the fistula.

\section{Hydrogen peroxide enhanced ultrasound (HPUS)}

Hydrogen peroxide (HP) enhanced ultrasound was used involving a diagnostic ultrasound system (type 3535, Bruel and Kjaer, Naerum, Denmark) with a $7 \mathrm{Mhz}$ rotating endoprobe (type 1850 , focal range $2-4.5 \mathrm{~cm}$ ) covered by a water-filled hard sonolucent cone (diameter $1.7 \mathrm{~cm}$ ), producing a $360^{\circ}$ view. The endoprobe was introduced into the rectum and serial radial images as well as video recordings were made of the distal part of the rectum, the puborectalis muscle and the anal canal. A fistula track could be seen as a tube-like hypoechoic image. A sphincter defect was seen as a hypoechoic interruption in the sphincter complex. After conventional US was performed, HP 3\% was introduced into the fistula track with a flexible intravenous cannula (Venflon (R), Ohmeda, Helsinborg, Sweden). Hereafter US was repeated as described previously. By infusion of HP, which generated the formation of small air bubbles, the hypoechoic fistulous track turns bright hyperechoic. The comparison of images with and without HP identified the course of the fistula and its extensions and allowed a distinction to be made between active fistulas and fibrotic tissue common in previously operated patients. The site of the internal opening, secondary extensions of the fistula and the presence of defects in one or both sphincters were also carefully recorded. The evidence of the internal opening was defined as a hypoechoic (conventional US) or echoic (HPUS) breach at the level of the submucosa. (Fig. 1)

\section{Classification}

The tracks were classified in single track or branched [6]. The relation to the sphincters was classified according to Parks classification [1] into four main groups:

- intersphincteric in which the track ramifies only in the intersphincteric plane and finally to the skin;

- transsphincteric, where the track passes from the intersphincteric plane through the external sphincter complex at varying levels into the ischiorectal fossa;

- suprashincteric, in which the track passes in the intersphincteric plane over the top of the puborectalis muscle, then downwards again through the levator plate to the ischiorectal fossa;

- extrasphincteric, in which the track passes from the perineal skin, through the ischiorectal fat and levator muscles into the rectum at another level than the pectinate line and outside the external sphincter complex altogether.

\section{Results}

\section{Never operated fistula-in-ano}

Forty-eight patients had a never operated fistula (with the exception of simple abscess drainage). Eighty percent had a single track fistula, $32(66 \%)$ of which were transsphincteric and seven (15\%) intersphincteric fistulas. In seven $(15 \%)$, the fistulas appeared to be sinus without a connection with the anal canal. Two patients (5\%) were found to have a double track, one transsphincteric with an intersphincteric track up to the supralevator space and the other patient a transsphincteric track with a horseshoe extension. No supra or extrasphincteric fistulas were found in the never operated group (Table 1 ).

Twenty-five of 32 transsphincteric fistulas developed after spontaneous abscess-drainage, while in seven the abscess was surgically drained. In only two of the seven patients with an intersphincteric fistula the fistula formed after a spontaneous abscess drainage. Moreover, the transsphincteric fistula with an intersphincteric track up 

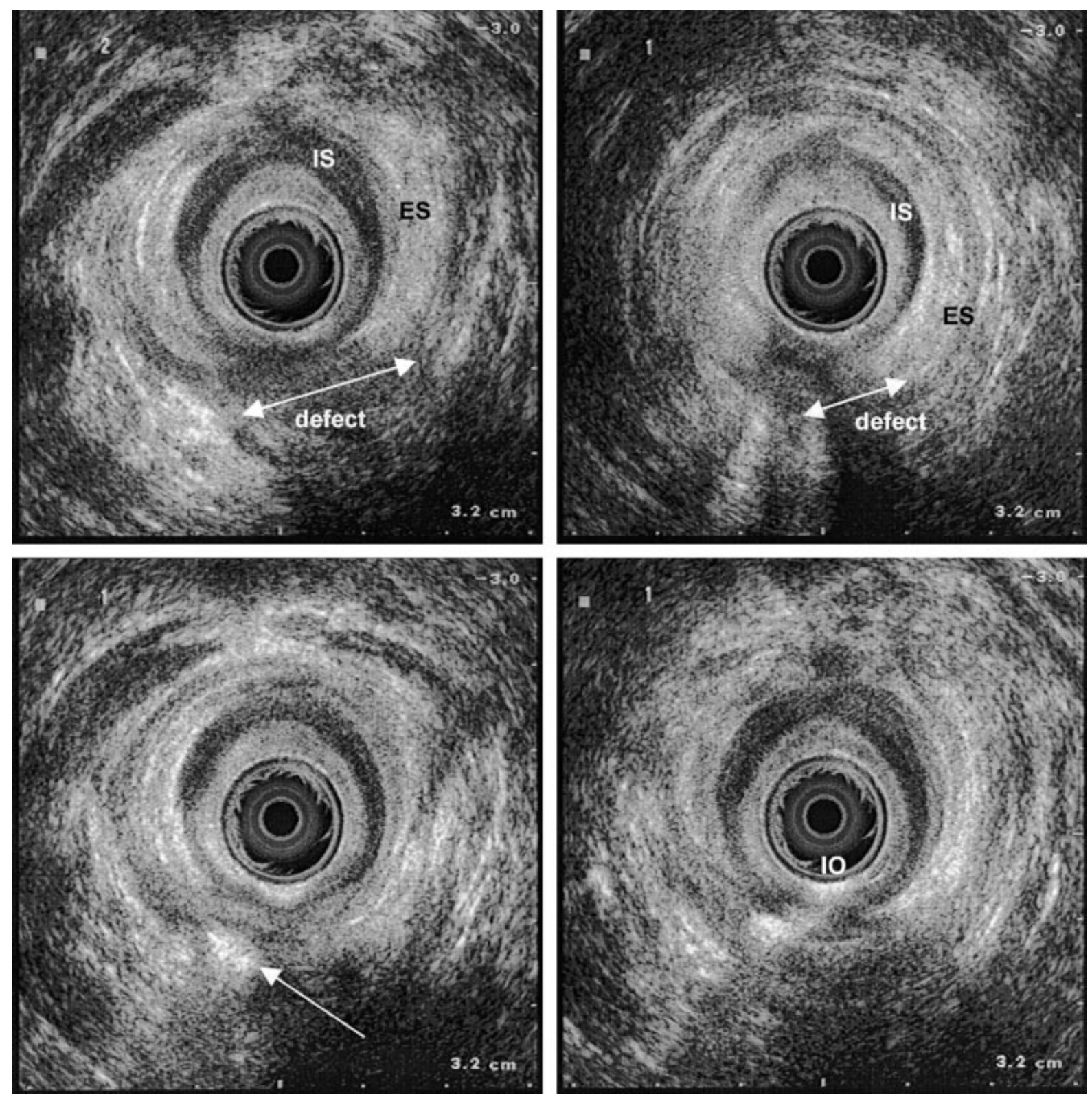

Figure I Transanal ultrasound showing a recurrent transsphincteric fistula. (a) Endosonography without hydrogen peroxide shows defect as a dark area clockwise from 5-7 h posteriorly in external anal sphinctern(ES) and internal anal sphincter (IS) and (b) more caudally. (c) After injection of hydrogen peroxide via the external opening the fistula-in-ano becomes visible (arrow) as a bright hyperchoic lesion and $(\mathrm{d})$ the internal opening (IO) can be detected.

to the supralevator space occurred after extensive abscess drainage.

\section{Recurrent fistula-in-ano}

Thirty-three patients had a recurrent fistula-in-ano (Table 1). The fistula was recurrent after fistulectomy in 10 patients, fistulotomy in 11 , mucosal advancement flap technique in two and a seton technique in three patients.
The seven other patients had already undergone two or more operations.

Nineteen patients $(57 \%)$ had a single inter- or transsphincteric track. Single track supra- or extra-sphincteric fistulas were found in five patients (15\%), all following a 'laying open' fistulotomy. The other nine patients had a fistula with more than one track $(27 \%)$. Six fistulas were inter- or trans-sphincteric, two had a horseshoe branch and four had a supralevator branch. Three of the other 
Table I Description of the fistulas and the extensions.

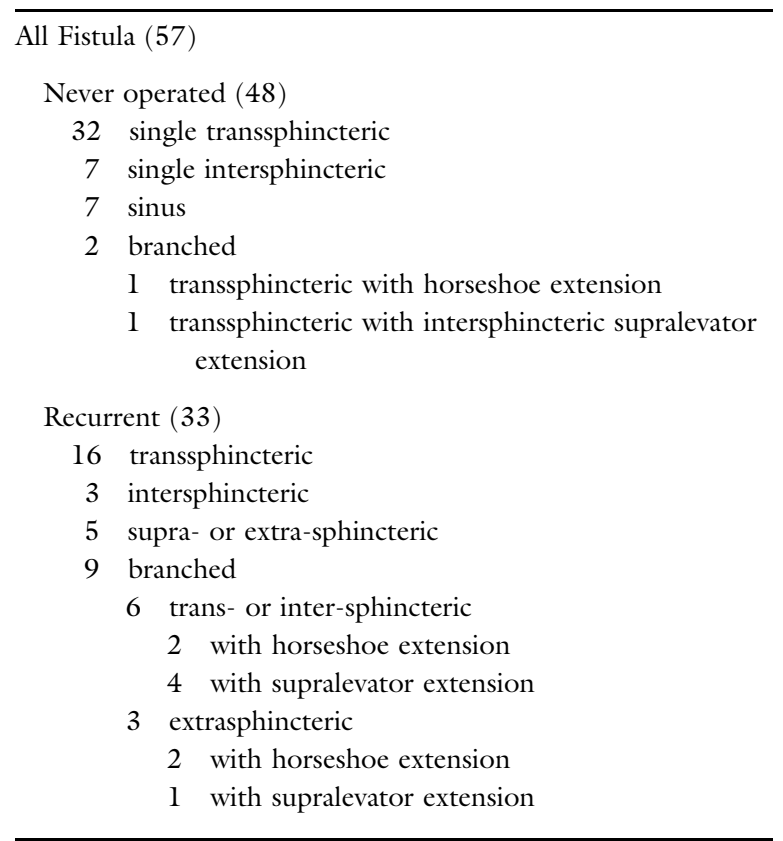

nine were found to be extrasphincteric fistula, two with a horseshoe extension and one with a supralevator branch.

\section{Discussion}

The cryptoglandular concept is currently the most widely supported theory about the aetiology of never operated fistulas-in-ano. Development of an intersphincteric abscess seems to be the first stage after the inflammation of one of the glands of Morgagni. This gland abscess situated in the intermuscular (intersphinteric) space has been called the cryptoglandular abscess. The anal glands can be localized cephaled, caudal or penetrating into the external sphincter. From here, the abscess can further develop intersphincterically and in some cases extend through some part of the external sphincter [1,6-12]. Morgan and Thompson [13] suggested that the intersphincteric abscess could follow the terminal fibroelastic conjoint longitudinal tendon septal fibres that transverse the external sphincter to reach the ischiorectal fossa. Parks et al. [1] based their classification on this theory and the examination of patients during surgical intervention by probing and the amount of sphincter mass divided. Parks et al. did not distinguish between never operated and recurrent fistulas in his classification.

As early as 1978, Eisenhammer [14] in his series of 800 patients, did not find the supra- or extra-sphincteric variations in never operated cryptoglandular fistula. Eisenhammer claimed that the primary cryptoglandular abscess/fistula never invades the supralevator space and is always inter- or trans-sphincteric, except for the recurrent cryptoglandular fistula which may extend its $\operatorname{track}(\mathrm{s})$ through the supralevator space. The findings were confirmed during surgical treatment in the studies of Fucini and other groups [15-18].

Hydrogen peroxide enhanced transanal ultrasound (HPUS) can confirm these important basic concepts [2-5] since it is an excellent method to classify perianal fistulas and correlates well with surgical findings (95\%) as we and others have demonstrated [2-5]. In addition, we have demonstrated that there was an additional value of HPUS of 33\% over endosonography without HPUS and $58 \%$ over digital examination [5]. In a large study of 180 patients, the fistula track and internal opening could be found with great accuracy with HPUS [5]. Limitations of the technique include exact localization of the internal opening making use of accurate criterions, loss of resolution due to air in the rectal ampulla, bubbling in the anal canal due to the injected hydrogen peroxide and the use of different transducers (e.g. a $7 \mathrm{mHz}$ transducer reveals more about the sphincter complex, whereas a 10 $\mathrm{mHz}$ tranducer reveals more about the submucosa). However, in experienced hands it is a rapid, simple and well-tolerated technique, which provides highly accurate information about the fistula track and the sphincter integrity before surgery.

A comparison between the endosonographic and surgical findings was not made in the present study since HPUS is proven to be a reliable technique in the above referenced articles and in our series some patients refused surgery and in the operated patients not all fistula tracks were explored prospectively during surgery. Magnetic Resonance Imaging (MRI) with or without endcoil is a competitive technique to HPUS to visualize adequately fistula tracks. Until now, both techniques have bot been compared directly but accuracy rates are comparable depending on the technique used and the type of fistula track analyzed [19-22]. The decision to use one of both visualization techniques should depend on the hospital's expertise and the accessability of the diagnostic tool. Presuming the diagnostic accuracy of HPUS and MRI are equal, HPUS seems more attractive considering the costs.

In our study, in which we visualized the fistula tracks with HPUS, we found that never operated cryptoglandular fistulas-in-ano are trans or intersphincteric fistula. A ramification was only found in two out of 48 patients. One patient had a horse-shoe extension. One patient had a supralevator branch. In this patient, an extensive abscess drainage had been performed before. It was only in the recurrent group that supra- and extra-sphincteric tracks were found. Similar conclusions were drawn in studies in which the fistula tracks were delineated during surgery. [14-18]. 
In conclusion, a never operated cryptoglandular fistula does not require any special investigation and can be treated by the standard surgical treatment. In recurrent fistulas, it is crucial to be informed about the fistula track because $43 \%$ of the fistulas are ramified or extend above the supralevator plane. Therefore, we advise performing hydrogen peroxide enhanced transanal ultrasound before treatment of the recurrent fistula.

\section{References}

1 Parks AG, Gordon PH, Hardcastle JD. A classification of fistula-in-ano. Br J Surg 1976; 63: 1-12.

2 Poen AC, Felt-Bersma RJF, Eijsbouts QAJ, Cuesta MA, Meuwissen SGM. Hydrogen peroxide enhanced transanal ultrasound in the assessment of fistula-in-ano. Dis Colon Rectum 1998; 41: 1147-52.

3 Choeng DM, Nogueras JJ, Wexner SD, Jagelman DG. Anal endosonography for recurrent anal fistulas: image enhancement with hydrogen peroxide. Dis Colon Rectum 1993; 36: 1158-60.

4 Choen S, Burnett S, Bartram CI, Nicholls RJ. Comparison between anal endosonography and digital examination in the evaluation of anal fistulae. Br J Surg 1991; 78: 445-7.

5 Cho D-Y. Endoscopic criteria for an internal opening of fistula-in-ano. Dis Colon Rectum 1999; 42: 515-8.

6 Thompson H. The orthodox conception of fistula-in-ano and its treatment. Proc R Soc Med 1962; 55: 754-6.

7 Corman ML. (1998 4th edn) Anorectal abscess. In Colon and Rectal Surgery. (ed. Corman ML), p. 224. LippincottRaven publishers, Philadelphia.

8 Seow-Choen F, Nicholls RJ. Anal fistula. Br J Surg 1992; 79: 197-205.

9 McColl I. The comparative anatomy and pathology of anal glands. Ann R Coll Surg Engl 1967; 40: 36-67.

10 Lilius HG. Fistula-in-ano. An investigation of human fetal anal ducts and intramuscular glands and a clinical study of 150 patients. Act Chir Scand Suppl 1968; 383: 1-88.
11 Goligher JC, Ellis M, Pissidis AG. A critique anal glandular infection in the aetiology and treatment in the idiopathic anorectal abscesses and fistulas. Br J Surg 1967; 54: 977-83.

12 Shafik A. A new concept of the anatomy of the anal sphincter mechanism and the physiology of defecation. VI. The central abscess: a new clinicopathologic entity in the genesis of anorectal suppuration. Dis Colon Rectum 1979; 22: 336-41.

13 Morgan CN, Thompson HR. Surgical anatomy of the anal canal with special reference to the surgical importance of the internal sphincter and conjoint longitudinal muscle. Ann Coll Surg Engl 1956; 19: 88.

14 Eisenhammer $S$. The final evaluation and classification of the surgical treatment of the primary anorectal cryptoglandular intermuscular (intersphinteric) fistulous abcess and fistula. Dis Colon Rectum 1978; 21: 237-54.

15 Fucini C. One-stage treatment of anal abscesses and fistulas. A clinical appraisal on the basis of two different classifications. Int J Colorect Dis 1991; 6: 12-6.

16 Bennett RC. A review of the result of orthodox treatment for anal fistulas. Proc R Soc Med 1962; 55: 756.

17 McElwain JW, Alexander RM, MacLean MD. Primary fistulectomy for anorectal abscess. a clinical study of 500 cases. Dis Colon Rectum 1966; 9: 181-5.

18 Hill JR. Fistulas and fistulous abscesses in the anorectal region: personal experience in management. Dis Colon Rectum 1967; 10: 421.

19 Hussain S, Stoker J, Schouten W, Hop W, Lameris J. Fistulain-ano: endoanal sonography versus endoanal MR imaging in classification. Radiology 1996; 200: 475-81.

20 Lunniss PJ, Barker PG, Sultan AH et al. Magnetic resonance imaging of fistula-in-ano. Dis Colon Rectum 1994; 37: 708-18.

21 DeSouza NM, Gilderdale DJ, Coutts GA, Puni R, Steiner RE. MRI of fistula-in-ano: a comparison of endoanal coil with external phased array coil techniques. J Comput Assist Tomogr 1998; 22: 357-63.

22 Halligan S, Bartram CI. MR imaging of fistula-in-ano: are endocoils the gold standard? Am J Roentgenol 1998; 171: 407-12. 